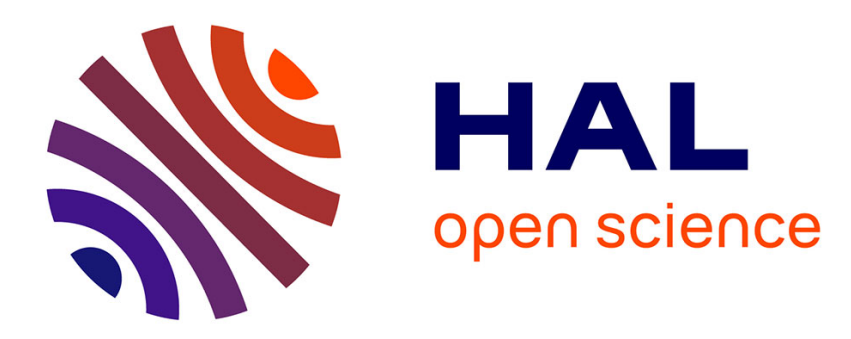

\title{
Le mépris des formes. Action publique, esthétique contemporaine et culture juvénile
}

\author{
Philippe Le Moigne
}

\section{To cite this version:}

Philippe Le Moigne. Le mépris des formes. Action publique, esthétique contemporaine et culture juvénile. Agora débats/jeunesses, 1995, 1, pp.57-68. 10.3406/agora.1995.1005 . hal-03433501

\section{HAL Id: hal-03433501 \\ https://hal.science/hal-03433501}

Submitted on 20 Jan 2022

HAL is a multi-disciplinary open access archive for the deposit and dissemination of scientific research documents, whether they are published or not. The documents may come from teaching and research institutions in France or abroad, or from public or private research centers.
L'archive ouverte pluridisciplinaire HAL, est destinée au dépôt et à la diffusion de documents scientifiques de niveau recherche, publiés ou non, émanant des établissements d'enseignement et de recherche français ou étrangers, des laboratoires publics ou privés. 


\section{Le mépris des formes. Action publique, esthétique contemporaine et} culture juvénile

Philippe Le Moigne

\section{Citer ce document / Cite this document :}

Le Moigne Philippe. Le mépris des formes. Action publique, esthétique contemporaine et culture juvénile. In: Agora débats/jeunesses, 1, 1995. Lieux de jeunes. pp. 57-68;

doi : https://doi.org/10.3406/agora.1995.1005

https://www.persee.fr/doc/agora_1268-5666_1995_num_1_1_1005

Fichier pdf généré le 05/04/2018 


\begin{abstract}
«A hearing For legitimate provocation»

Public action, contemporary aesthetics and youth culture

This article looks at the diverse logistics which provide a back-up, both from the state and local authorities to the public plebiscite of contemporary art. These aesthetic, radical and iconoclastic canons have a great deal in common with both the past and present forms of youth culture. However, the territories of these two cultures only very rarely overlap. Young people's creative achievements, when simply labelled as «dangerous self-expression» nevertheless continue to be associated with private, commercial and «intimist» business. On the other hand, public promotion of the visual arts relates rather more to a "fashionable radicalism» ; it contributes to a hearing for legitimate provocation, leading to tensions but also to a reappraisal of cultural qualifications and skills.
\end{abstract}

\title{
Resumen
}

El espacio de provocaciones legitimas

Acción publica estética contemporánea y cultura juvenil Este artículo presenta las diferentes lógicas de acción que sostienen, tanto de parte del Estado como de las municipalidades, el plebiscito público del arte contemporáneo. Esos cánones estéticos, radicales e iconoclastas, mantienen numerosas afinidades con las formas antiguas y modernas de la cultura juvenil. Sin embargo, los territorios de esas dos culturas no se imbrican nunca realmente. La creación de los jóvenes, cuando no es reducida al estatuto de "expresión peligrosa", queda asociada a una explotación privada, comercial o "i nt i mista". Por el contrario, la promoción pública de la artes plásticas se asemeja, más bien, a " un radicalismo mundano "; contribuye a la formación de un espacio de provocaciones legítimas, portador de tensiones, pero también de una recomposición de las calificaciones y de las competencias culturales.

\section{Zusammenfassung}

Der Raum der legitimen Provokationen

Öffentliche Aktion, zeigenössische Ästhetik und jugendliche Kultur

Dieser Artikel legt die verschiedenen Handlungslogiken dar, die, sowohl von Seiten des Staates als auch der Stadtverwaltungen, das öffentliche Plebiszit für zeitgenössische Kunst stützen. Diese ästhetischen Kanons, radikal und bilderstürmerisch, unterhalten zahlreiche äff initäten zu den alten und modernen Formen der jugendlichen Kultur. Trotzdem kommen die gebiete dieser beiden Kulturen nie wirklich zu einer Deckung. Wenn die Schöpfung der jungen Leute nicht auf den Stand des "gefährlichen Ausdrucks» reduziert ist, bleibt sie dennoch einer privaten, kommerziellen oder «intimistischen» Nutzung verbunden. Im Gegensatz dazu ist die öffentliche Förderung der plastischen Künste eher dem «mondänen Radikalismus» verwandt. Sie trägt zur Schaffung eines Raumes der legitimen Provokationen bei, der zwar Träger von Spannungen ist, aber auch die Qualifikationen und kulturellen Kompetenzen wiedererstehen lässt.

\section{Résumé}

Cet article présente les différentes logiques d'action qui supportent, aussi bien du côté de l'Etat que des municipalités, le plébiscite public de l'art contemporain. Ces canons esthétiques, radicaux et iconoclastes, entretiennent de nombreuses affinités avec les formes anciennes et modernes de la culture juvénile. Néanmoins, les territoires de ces deux cultures ne se recouvrent jamais réellement. La création des jeunes, lorsqu'elle n'est pas réduite au statut d' «expression dangereuse», demeure associée à une exploitation privée, commerciale ou «intimiste». En revanche, la promotion publique des arts plastiques s'apparente plutôt à «un radicalisme mondain» ; elle contribue à la formation d'un espace de provocations légitimes, porteur de tensions mais aussi d'une recomposition des qualifications et des compétences culturelles. 


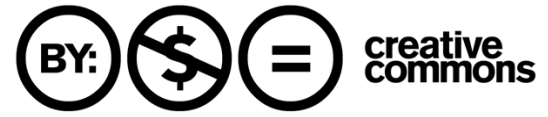




\section{art contemporain}

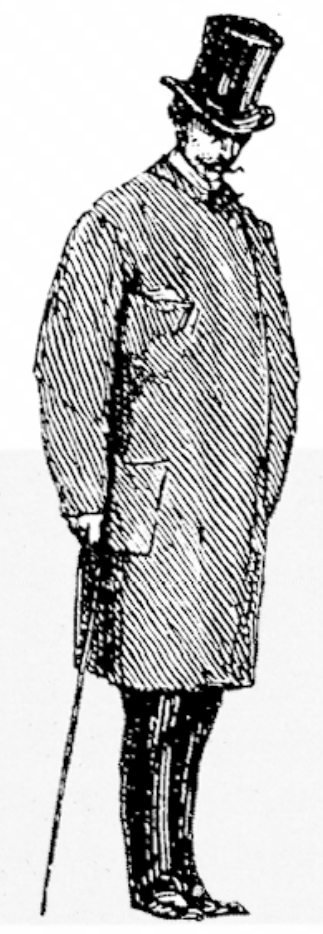

toire d'Etudes et de Recherche Sociales

IRTS de Haute-Normandie, BP 5, 76380

Canteleu-Rouen

Cet article présente les différentes logiques

d'action qui supportent, aussi bien du côté de l'Etat que des municipalités, le plébiscite public de l'art contemporain. Ces canons esthétiques, radicaux et iconoclastes, entretiennent de nombreuses affinités avec les formes anciennes et modernes de la culture juvénile. Néanmoins, les territoires de ces deux cultures ne se recouvrent jamais réellement. La création des jeunes, lorsqu'elle n'est pas réduite au statut d" "expression dangereuse", demeure associée à une exploitation privée, commerciale ou "intimiste». En revanche, la promotion publique des arts plastiques s'apparente plutót à «un radicalisme mondain" ; elle contribue à la formation d'un espace de provocations légitimes, porteur de tensions mais aussi d'une recomposition des qualifications et des compétences culturelles.

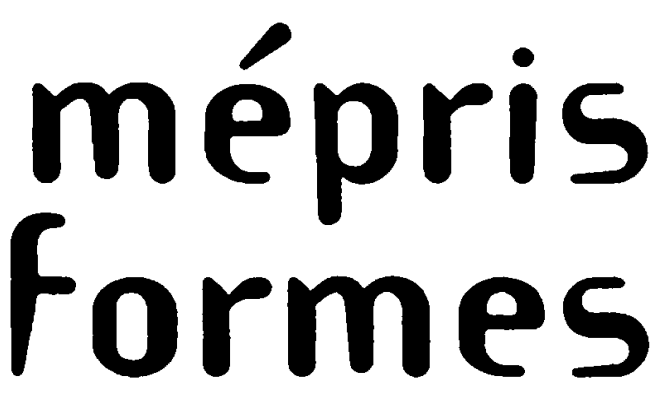

ACTION PUBLIQUE, ESTHÉTIQUE CONTEMPORAINE ET CULTURE JUVÉNILE

$$
\text { par Pbilippe Le Moigne }
$$

L'histoire française du soutien public à la culture, et plus particulièrement l'aide à la création, est intimement mêlée aux vicissitudes des marchés artistiques privés. Cette histoire, souvent heurtée, associe découpages et recouvrements. Au début du siècle, le mouvement impressionniste, nourri par la rupture avec l'académisme, a donné naissance aux deux figures du marchand et du critique ${ }^{1}$. Jamais sans doute, autant qu'à cette époque, l'autonomie de la création n'a été si forte ${ }^{2}$. Mais, par la suite, l'opéra, le théâtre ainsi que la plupart des secteurs artistiques, menacés par une crise économique inextricable, n'ont dû leur salut qu'à l'expansion des subventions publiques ${ }^{3}$. Paradoxalement, l'essor de l'administration de la culture débute réellement au moment où le marché français cesse de dicter le contour des réputations et des cotes. La politique pompidolienne, résolument ouverte à la création contemporaine, préfigurait ainsi l'action d'Etat conduite dans les années 1980 ; les adversaires d'hier, résolument critiques à l'égard du dirigisme et de l'élitisme ministériels, ayant investi à

\footnotetext{
' White $H$. et White C., La carrière des peintres au XIX' siecle, Paris, Flammarion, 1991.

2 Bourdieu P.. Les régles de l'art. Paris. Le Seuil. 1992.

3 de Saint-Pulgent M.. Le syndrome de l'opéra. Paris. Robert Laffont. 1991.
} 
la faveur du changement de majorité la plupart des postes décisionnels clés ${ }^{4}$.

Comprendre quel a été l'esprit de l'action publique et mesurer l'accueil réservé par les municipalités aux options ministérielles permet de mieux saisir l'évolution des liens tissés entre le développement culturel et la culture juvénile. La remise en cause des formes convenues, des traditions et des situations acquises définit semble-t-il un souci commun aux modes d'expression salués de part et d'autre. Pourtant, cette identité de principes n'a pas donné lieu, loin s'en faut, à la création de véritables systèmes de coopération, elle n'a pas non plus suggéré la formation d'une communauté d'espaces créatifs. Chacun de ces univers symboliques diffuse dans des systèmes de promotion et des lieux de création résolument différenciés. Ce texte a pour objet d'analyser quelques-unes des dimensions de ce phénomène.

\section{Le radicalisme mondain : le plébiscite} administratif des arts plastiques

Recherche et création : l'iconoclasme légitime

La promulgation des paris esthétiques les plus radicaux au rang d'action prioritaire amène à considérer avec une certaine circonspection l'idée selon laquelle la stratégie politique et, par suite, la promotion du consensus obligeraient au conservatisme. L'intention portée par les décideurs aux jeux de formes, aux expériences créatrices, en un mot, à la recherche artistique, apporte sur ce point un clair démenti. Cette orientation politique fait suite à une autonomisation grandissante du phénomène culturel. Elle n'entérine pas seulement une définition détachée, extra-mondaine, de l'art. Le statut de la création et de la pratique des activités culturelles a acquis en légitimité. Elles situent aujourd'hui un espace de discours et de conduites depuis lequel des règles spécifiques peuvent être édictées. Ce phénomène essaime dans la plupart des registres et des répertoires culturels, qu'ils soient financés et encadrés par l'administration ou le secteur marchand. De ce point de vue, l'Etat, au même titre que l'industrie culturelle, introduit bel et bien une rupture avec le classicisme. Mais, le secteur public importe de nouveau sans doute, cette fois sur le terrain de l'innovation et de la provocation, le jeu des convenances et des hiérarchies propres à l'univers mondain.

Ce radicalisme élitaire dénonce peu le travail «vulgaire» des formes, c'est-à-dire l'absence d'abstraction, il jette plutôt l'opprobre sur le traditionalisme et inscrit la critique de l'obsolescence au rang des pratiques les plus routinières ${ }^{5}$. A ce titre, une relation de réelle proximité peut être établie entre l'art contemporain et l'une des composantes principales de la culture des jeunes '. Pour autant, ces affinités ne tiennent pas lieu de connivence. La création demeure structurée par des processus extrêmement discriminants. Elle consacre des espaces, des répertoires et des secteurs d'activité résolument

\footnotetext{
4 Verger A.. "Le champ des avant-gardes", Actes de la Recherche en Sciences Sociales, 1991, pp. 2-40.

${ }^{5}$ L'esthétique contemporaine, depuis Marcel Duchamp. n'a cessé de chercher les voies d'une narration antistique fondatrice. Poussé au paroxysme, ce pari conduit à affubler les objets les plus quotidiens d'une qualification plastique. La signature de l'artiste apposée sur une pelle ou sur une cravate ("ceci est une pelle", "ceci est une cravate") suffit alors à coter l'outil ou le vêtement d'un statut esthétique. Danto A.. La transfiguration du banal, Paris, Le Seuil, 1989 et Lamy Y., “Changement culturel, marché des oeuvres, théorie esthétique", Genèses, n², pp. 178-191.

6 Lanalyse dẹs mouvements culturels des années 1960 pointe en effet un attrait constant pour la re-définition des limites et des frontières. Les expériences de toutes sortes y ont acquis un statut emblématique, devenu aujourd'hui quasi légendaire. Martin B., Sociology of contemporary cultural change, Oxford, Basic Blackwell, 1985.
} 
disjoints. Morcelées en une multitude d'organisations, ces expériences restent différenciées et hiérarchisées selon qu'elles sont promues par les media et l'industrie du disque ou les structures de formation et d'exposition publiques. Cette dissociation s'étend aux modes d'élection et aux gratifications qui les accompagnent. Les artistes consacrés, souvent réfractaires à toute forme d'assimilation, peuvent rarement, à moins de demeurer en porte à faux, mêler gratifications monétaires et gratifications symboliques.

Ce principe définit l'organisation de la culture qui, en retour, en entretient l'actualité. D'un côté, l'institutionnalisation renforce auprès des agents publics la dépréciation du commerce de l'art, par ailleurs, elle autorise la constitution de marchés protégés de la création, résolument autonomes et de plus en plus éloignés de la «consécration populaire» ${ }^{`}$. De l'autre, l'absence de compétences sanctionnées par le droit conduit les représentants du commerce privé à délaisser la formation et l'encadrement artistique, par suite, elle les incline à recourir à une exploitation stratégique et souvent épurée des mouvements juvéniles «les plus porteurs» ${ }^{8}$.

Le sort de la création des jeunes offre ainsi une image en creux des circuits de légitimation. Confinée à l'amateurisme par l'administration culturelle, réduite à une somme d'expériences concurrentes ou souterraines par l'institution scolaire, cette création n'accède à la reconnaissance et au succès qu'au prix d'une exploitation controversée, industrielle et mercantile. Cette position se prête à de multiples projections. Démunie d'alternatives réelles, la pratique des jeunes offre en effet un terrain propice à de multiples expériences, un espace où peut s'appli- quer le jeu des oppositions, des calculs, des démonstrations et des mots d'ordre.

Des groupes musicaux ont bien cherché à sortir de cet enfermement en suscitant la création de labels autonomes. Telle est l'origine de la maison de disques Virgin. Une partie de la production des groupes rap est également organisée aujourd'hui à partir d'une telle tentative. Néanmoins, la loi du marché, et de la distribution en particulier, contraignent la plupart de ces secteurs musicaux à faire allégeance avec les grandes manufactories. Or, l'innovation, une fois passée sous les fourches caudines de la commercialisation, ne peut plus guère échapper aux (re)traductions esthétiques imposées par la rentabilité. Ce transfert ampute généralement la création de ses dimensions les plus provocatrices, à moins que l'industrie du disque ne cherche à tirer profit de l'audace de certains groupes en suscitant la formation d'un style résolument iconoclaste, comme ce put être le cas pour la musique punk. Néanmoins, les expériences qui tentent d'ignorer ces procès de «normalisation» sont souvent frappées d'interdictions. C'est là une constante de l'histoire de la culture rock et aujourd'hui des concerts rap.

\footnotetext{
${ }^{7}$ Ce phénomène est tout à fait prégnant dans le domaine de la création musicale. Quelques compositeurs seulement occupent à la fois les fonctions décisionnelles du sommet de l'Etat et dirigent la programmation des radios publiques. notamment de France Musique. Ce cumul de mandats favorise la cooptation et la distribution de gratitications réciproques. Ainsi, les droits liés à la diffusion radiophonique des oeuvres contemporaines sont, en raison de la priorité donnée par les programmateurs publics à l'écoute de leurs confrères. sans rapport aucun avec l'audience réelle de ce type de musique. Menger P.M., Le paradoxe du musicien, Paris, Flammarion, 1983.

${ }^{8}$ Les réseaux radiophoniques exercent une influence remarquable sur la constitution des styles musicaux. Ce phénomène ne paraît èpargner aucun genre, dut-il être résolument critique à l'instar du protest song. Peterson R., "The unnatural history of rock festivals : an instance of media facilitation", Popular music and society, n², 1973, pp. 98-132.
} 


\section{Le sort de la création des jeunes offre ainsi une image en creux des circuits de légitimation.}

territorial est conséquent. En un mot, le recours au secteur privé est plus fréquent en

Contrastes et décalages : l'espace municipal de la culture

L'organisation publique de la culture n'a pas été réellement modifiée par les lois de décentralisation. Une remise en cause du pouvoir de tutelle n'a guère de sens ici : la culture n'a jamais été réellement inscrite au Plan. Par ailleurs, le développement local n'est soumis à aucune obligation, il demeure à la discrétion des municipalités. La liberté d'initiative et de recrutement ampute néanmoins l'échelon local de toute compétence réelle. Dans ce secteur, seul l'Etat est en effet habilité à homologuer les titres et les qualiffcations. L'implantation d'une structure nationale (Conservatoire National de Musique, Conservatoire Dramatique National...) sur le sol communal requiert nécessairement la signature d'une convention bipartite. Par ailleurs, cette contractualisation implique le recrutement de fonctionnaires d'Etat.

Le recours à l'expertise ministérielle prive donc les élus locaux d'une partie de leur pouvoir décisionnel ${ }^{9}$. C'est pourquoi le développement communal, en expansion continue depuis les années 1970, s'est souvent organisé aux marges de l'administration culturelle ${ }^{10}$. Le recours au tissu associatif, la construction de salles à «grands spectacles», la programmation d'artistes issus des filières commerciales, sont autant de traits caractéristiques de l'action locale. La probabilité d'un tel développement est toutefois d'autant plus forte que le budget municipal est réduit et que le degré d'urbanisation du contexte agglomération, en revanche, il est souvent résiduel dans les métropoles régionales ou les centres urbains des départements ruraux.

La différenciation des espaces publics de la culture résulte d'une équation décisionnelle. Les municipalités doivent en effet tenter d'obtenir la meilleure péréquation entre rentabilité économique, fréquentation et réputation artistique. Là où la concurrence métropolitaine confère à l'intégration des filières administratives le statut d'un pari, les municipalités ont plutôt tendance à miser sur une politique de diffusion. Le recours privé s'avère moins coûteux, qui plus est, il draine souvent un public déjà constitué ${ }^{11}$. Ce choix prive l'action locale d'un rayonnement national mais il assure néanmoins les villes d'agglomération d'un réel succès de fréquentation. Les villes-centres n'ont pas à faire un tel compromis. Au contraire, la centralité, géogra-

\footnotetext{
${ }^{9}$ Le Moigne $\mathrm{Ph}$., "Les politiques municipales de la culture : du Développement Culturel au conditionnement public (1977-1990)", Table ronde : les politiques culturelles municipales, Paris, FNSP. CHEVS. Fév. 1994, à paraître à la Documentation Française.

${ }^{10}$ Le financement public de la culture est en constante progression depuis 1970. La contribution des municipalités représente $50 \%$ des dépenses consenties par le secteur administratif et les institutions de représentation politique. Timbard O., "Les collectivités locales dans le financement public de la culture en France", Economie et culture. Culture en devenir et volonté publique, Vol. II, Paris, La Documentation Française, pp. 105-127.

"Comme l'a montré $W$. Baumol, l'économie du spectacle est nécessairement déficitaire. En effet, les coûts de fonctionnement, de production, augmentent ici bien plus vite que ne progressent les recettes. Une telle tendance peut être contenue, voire inversée, pour les concerts de musique rock ou de variétés. En revanche, dans le domaine de la création - qu'il s'agisse du theâtre, de la musique classique ou bien encore de l'opera, seule une augmentation extrêmement prohibitive du prix des places pourrait contrecarrer la hausse tendancielle des coûts. Baumol W. et Bowen W., Performing arts : the economic dilemma, New Yok, The Twentieth Century, 1966.
} 
phique ou décisionnelle, tient lieu d'exhortation à la surenchère. Ces villes misent généralement sur une participation directe à la constitution de la valeur et des talents. C'est pourquoi les structures de formation et de création y occupent une place aussi centrale. Ces communes jouissent d'une meilleure réputation auprès des conseillers artistiques des ministères mais elles sont davantage endettées et connaissent dans la plupart des cas de véritables carences d'audience.

La cartographie du développement public n’a donc pas nécessairement prise avec la géographie des pratiques culturelles. Paradoxalement, cet écart est sans doute plus réduit là où les contraintes décisionnelles sont les plus fortes. Par ailleurs, la confrontation des options municipales a concouru peu à peu au déplacement des espaces d'expression et de création collective. Le financement des salles destinées à la programmation de musique rock, souvent remis en cause par les notables métropolitains, a été progressivement pris en charge par l'agglomération. A l'inverse, le théâtre contemporain, héritier des mouvements contestataires des années 1970 , a d'abord été soutenu par les municipalités de banlieue. Ce type d'expression, une fois couronné par la critique, a été largement financé par les métropoles, au point de constituer sans doute le fleuron culturel de ces villes ${ }^{12}$.

L'expansion publique oblige donc parfois les créateurs et les spectateurs à investir d'autres espaces ou à solliciter d'autres formes de soutien. Ce découplage est plus diffus et moins problématique dans le cadre des territoires fortement urbanisés. Là, la multiplication des initiatives municipales permet une large couverture des pratiques. En revanche, le contexte rural limite de fait l'éventail des propositions à quelques foyers de développement au plus. Cette particularité accorde une visibilité sans doute inégalée aux initiatives municipales. Ici, le plébiscite de la création contemporaine est d'autant plus mal reçu qu'il s'adresse à une population encore majoritairement marquée par les sociabilités ouvrières et bourgeoises ${ }^{13}$. Pourtant, ces opérations constituent, avec le soutien au patrimoine, l'un des traits les plus caractéristiques des villes moyennes du milieu rural. Associées depuis longtemps à l'action culturelle de l'Etat, notamment à travers le système des chartes inauguré par la politique giscardienne, ces villes ont été largement bénéficiaires des premières mesures prises dans le cadre de la régionalisation. La création des Fonds Régionaux d'Art Contemporain fait suite à cette relation longtemps entretenue et élargie maintenant aux instances de représentation régionale ${ }^{14}$.

Les FRAC, créés en Juin 1982, sont organisés par une convention tripartite. La Région contribue avec l'aide de l'Etat à l'achat des ocuvres, les municipalités s'engagent à mettre à disposition des locaux d'exposition. Souhaitant faire partager au plus grand nombre la présentation des artistes les plus innovants, les concepteurs des FRAC ont cherché à renouveler la pratique

\footnotetext{
12 Malet V.. Les politiques publiques locales en matière culturelle: la ville de Bordeaux et sa perriphérie. Bordeaux, MSHA, 1982.

${ }^{13}$ La presentation de l'art contemporain en milieu ouvrier n'a pas toujours été parfaitement maîtrisée. Le fait est que des plasticiens ont parfois cherché à proposer à ces populations une sorte d'esthétisation de l'univers usinier. Pour les ouvriers des régıons sinistrées. l'utilisation à des fins plastiques des matériaux liés à l'activité industrielle a eu, on l'imagine aisément, valeur d'afiront. II n'est donc pas ètonnant que les expériences conduites dans ce sens se soient soldées pour la plupart par une destruction massive des oeuvres. Gambioni, D. "Méprises et mépris. Elèments pour une étude de l'iconoclasme contemporain", Actes de la Recherche en Sciences Sociales, $n^{\circ} 49,1983$, pp. 2-18. 14 D'Angelo M., Douze villes et le changement culturel. Les effets du Ministère de la Culture au plan local depuis 1981. Paris, SERCSO, 1985, Friedberg E., Urtalino P., D'Angelo M. et Maniveau S., La décentralisation culturelle au service des régions, Paris, SER-CSO, 1984.
} 
muséale en favorisant l'éclectisme et la diversification des lieux d'exposition. Dans les faits, l'Etat - très présent lors du choix des œuvres - a insufflé une visée assez homogène à l'entreprise. Il en est ressorti une politique d'achat résolument tournée vers les plasticiens de réputation nationale, sinon internationale.

\section{La fréquentation suscitée}

\section{L'avant-garde en question}

L'art contemporain cristallise la plupart des tensions qui parcourent le champ culturel. De fait, la légitimité des expériences les plus radicales a souvent été établie sur la base d'une critique virulente de l'académisme. La composition aléatoire, les performances picturales se réclament d'une définition artistique fondatrice. Elles s'opposent donc à l'opéra classique ou à la création figurative qui restent soumis à une fonction narrative. Le postulat d'autonomie rencontre l'hostilité des sociétés picturales locales, héritières pour la plupart des grandes Ecoles de la peinture figurative, mais aussi des membres de l'enseignement artistique. En effet, ce parti remet en question la valeur de l'héritage et dénonce en particulier l'enfermement auquel conduit l'emploi systématique de normes d'apprentissage, qu'il s'agisse des esquisses ou des règles de déchiffrage. Enfin, le postulat d'avantgarde autorise les acteurs de la création contemporaine à réclamer un développement marqué des financements publics consacrés à la prospection et à la recherche. Or, les arbitrages ministériels ont souvent plaidé en faveur d'un tel argumentaire, réduisant d'autant la part des crédits alloués aussi bien à la formation qu'à la sensibilisation aux pratiques artistiques ${ }^{15}$.

Les études consacrées à l'impact de la créa- tion contemporaine aiguisent le débat. Les partis esthétiques, consacrés par l'organisation décisionnelle et budgétaire de l'administration culturelle, ont bel et bien, lorsqu'ils sont connus du public, valeur de référence. Néanmoins, il s'agit là d'une légitimité de convenance plus que d'une réelle consécration. Si on mesure cet impact à la fréquentation des structures d'art contemporain (CAPC, FRAC, Théâtre conventionné...), l'impression est tout autre ${ }^{16}$. Ces espaces rencontrent peu le public. Par ailleurs, les audiences sont souvent composées de créateurs ou de techniciens, c'est-à-dire des acteurs sinon des auteurs des productions contemporaines ${ }^{17}$.

Pour autant, ce résultat ne compromet pas réellement le prestige public de telles expériences. Les créateurs peuvent opposer à leurs détracteurs de nombreux arguments. Il leur suffit de rappeler que la fréquentation ne constitue qu'un piètre indice de valeur, que l'absence de public s'apparente plutôt à un processus récurrent de l'Histoire de l'art, en un

\footnotetext{
15 C'est là tout le sens du conflit qui opposa Pierre Boulez à Marcel Landowski. De fait, la création de I'IRCAM, puis la construction de l'Opéra Bastille, ont réduit la probabilité d'un renouvellement important de la contribution d'Etat au développement des structures de formation locales. Rappelons que le financement de l'Opéra Bastille génère à lui seul aujourd'hui près de $25 \%$ des dépenses effectuèes par la Direction Ministèrielle à la Musique. Menger P.-M., Le paradoxe du musicien, op. cit..

${ }^{16}$ Rappelons que $2 \%$ seulement des ouvriers iront au moins une fois au théâtre dans leur vie. Guy J.-M. et Mironer L.. Les publics du théâtre, Paris, La Documentation Française, 1988. La fréquentation des structures d'art contemporain connait le même sort. Comme pour le théatre, on assiste bien à une augmentation du volume des entrées. Mais. cette croissance masque en fait une réelle incapacitè à recruter parmi les catégories traditionnellement les plus éloignées du secteur public de la culture.Donnat O., Les Français face à la culture : de l'exclusion à l'éclectisme, Paris, Editions de la Découverte, 1994.

17 Menger P.-M., "L'oreille spéculative : consommation et perception de la musique contemporaine", Revue Française de Sociologie. XVII, 1986, pp. 445-479.
} 
mot, que la production des nouveaux canons esthétiques n'est jamais immédiatement couronnée par la consécration populaire. La thèse du «décalage» ou du «retard» cautionne ainsi un jeu spéculatif d'envergure sans que pour autant quiconque soit assuré de la formation à terme d'un nouveau langage créatif ${ }^{18}$.

De leur côté, les élus locaux, engagés dans la défense et la promotion du scrvicc public, ne peuvent rester sans agir face à un manque criant de fréquentation. La répétition d'une telle éventualité les a amenés peu à peu à concevoir un certain nombre de parades. L'organisation municipale a élargi ainsi progressivement son action à des fonctions proches de celles traditionnellement assurées par les agences artistiques. Elle a affecté des personnels aux tâches de sélection et de présentation des oeuvres. Surtout, elle a cherché à mobiliser les enseignants, à obtenir d'eux une «caution scolaire». A terme, l'éventail des dispositions et des incitations a permis une croissance réelle des audiences. Néan. moins, la question demeure de savoir si un tel volontarisme n'a pas tout simplement contribué à la formation d'un public «captif».

La caution scolaire et la recomposition des savoirs

La fréquentation des FRAC illustre bien un tel phénomène. Les données recueillies en Aquitaine, pour la saison 1988-1989, livrent deux types d'enseignements (Annexe). Tout d'abord, le nombre d'entrées est relativement modeste. En moyenne, 20 personnes par jour seulement se rendent aux expositions. Par ailleurs, la structure de la fréquentation est fortement marquée par la présence du public scolaire. Ces visites représentent $21 \%$ de l'ensemble des entrées. Pour certaines expositions, cette proportion s'élève à $82 \%$. Ce résultat est le fruit de facteurs et d'événements convergents. Il découle de la mobilisation des acteurs dont la position et la légitimité dépendent pour tout ou partie de leur capacité à incarner l'espace public local. En un mot, conservateurs, enseignants et ćlus ont à divers titres intérêt à susciter une telle participation.

L'esthétique contemporaine soulève la crainte des sociétés académiques et rencontre, éventuellement, la critique de la presse locale. Le débat, initialement suscité par la valeur «problématique» des oeuvres, gagne ainsi progressivement le terrain décisionnel. Le gouvernement municipal est taxé d'arbitraire, l'organisation des expositions est placée au rang des dépenses abusives. Pour sortir de l'impasse, les mairies ont tendance à déplacer la controverse sur le terrain de la procédure. Il revient alors à l'administration culturelle de jouer le rôle ingrat d'exutoire. L'argument des élus se décompose ainsi : les expositions sont conçues au mépris de la spécificité locale ; les agents du FRAC ne tiennent pas compte des publics et rechignent à assortir leur entreprise d'actions de sensibilisation. Pour contrecarrer de tels «débordements», les élus se proposent donc généralement de reconquérir la mise en oeuvre. Avec l'aide des conservateurs, ils entreprennent alors de construire - ou de faire valoir - un projet mieux intégré ${ }^{19}$. Le musée municipal reçoit pour mission de sélectionner

\footnotetext{
18 II s'agit là d'une question débattue par les sciences sociales. Pierre Bourdieu accorde semble-t-il crédit à la thèse du "décalage". Par conséquent, l'esthétique contemporaine constitue bel et bien selon lui une avant-garde. En revanche. Claude LeviStrauss défend une position beaucoup plus sceptique. Selon lui, il s'agit là tout au plus d'un ensemble de signes, en aucun cas, ces expériences ne forment langage. Bourdieu P., "Le marché des biens symbolıques", L'Année sociologique, $n^{\circ} 22,1977, p p .49$ 126 ; Levi-Strauss C., Le cru et le cuit, Paris, Plon, 1964.

19 Four P.-A., "La compétence contre la démocratisation? Création et re-création des Fonds Régionaux d'Art Contemporain", Politix, n²4, 1993, pp. 95-114.
} 
les œuvres et d'associer l'ensemble des représentants culturels locaux à la définition et à la présentation des expositions. Cette stratégie conduit de fait à écarter des catalogues la majorité des prestations les plus radicales. La résolution des tensions a donc un prix : le retour à un certain conservatisme. Pour autant, l'adhésion des conservateurs à de tels projets est d'emblée acquise. En effet, ils peuvent de la sorte afficher de nouvelles compétences, c'est-à-dire élargir leur fonction à des activités qui dépassent de loin le cadre étroit de la conservation ${ }^{20}$.

La collaboration des enseignants est plus aléatoire. Elle peut être motivée par une souscription réelle à l'esthétique contemporaine. Mais elle est également liée tout à la fois aux pressions exercées par l'organisation scolaire, en particulier par l'inspection académique, et aux gratifications induites par l'acquisition d'une spécialisation culturelle. L'érosion de la culture lettrée, des Humanités, oblige en effet les enseignants à construire de nouvelles légitimités ${ }^{21}$. D'un côté, la massification scolaire, c'est-à-dire l'ouverture de l'institution à des publics autrefois absents de l'enseignement, de l'autre, le succès et par conséquent la banalisation grandissante des oeuvres classiques, contraignent les instituteurs mais aussi les professeurs du secondaire à de nouveaux positionnements. En un mot, ils ne sont plus dépositaires en droit de l'héritage culturel national.

Le même phénomène s'applique aux bibliothécaires. Longtemps associé à l'érudition, le contenu des compétences et des qualifications professionnelles a peu à peu évolué vers une définition technique. La croissance du taux de scolarisation, la mise à disposition de nouveaux outillages, ont conduit les nouvelles générations de professionnels à miser sur la rationalisation des opérations de gestion et de codage. Ce déplacement de légitimité leur permet de faire front aux critiques et aux demandes d'un public dont les connaissances se sont élargies. Une telle réorientation de la pratique ne fait donc pas seulement écho à une «amélioration» technique, elle permet également de faire écran aux nouvelles sollicitations du lectorat et de réintroduire la distance en lieu et place d'une proximité culturelle disqualifiante ${ }^{22}$.

L'ceil innocent: le jeune au secours $d u$ visionnaire

Cette conjonction d'éléments apparaît d'autant plus facilement qu'elle peut prendre appui sur un écheveau d'interprétations et de rationalisations communes. Ce système cognitif, plus ou moins organisé et formalisé, emboîte une vision romantique de la jeunesse et une conception substantialiste de l'avantgarde. Selon ces schémas, l'incompréhension des œuvres contemporaines est à mettre au compte des pesanteurs historiques : l'adulte ne peut faire abstraction des conventions héritées, il est d'emblée «fixé» à la tradition. En revanche, la «virginité» sensorielle et l'«innocence» culturelle de l'enfant ou de l'adolescent autorisent de nouvelles constructions, de nouveaux apprentissages.

Le mythe de «la page blanche» parcourt l'ensemble des représentations émises à

\footnotetext{
20 Heinich N., Pollak M., "Du conservateur de musée à l'auteur d'expositions : l'invention d'une position singulière", Sociologie du Travail, $n^{\circ}$ 1-89, pp. 47-78.

21 Dubet F., Les Iycéens. Paris, Le Seuil, 1991.

22 Seibel B., Au nom du livre. Analyse sociale d'une profession : les bibliothécaires. Paris, La Documentation Française, 1987. Les postures adoptées par les professionnels pour faire face à la montée du pluralisme culturel restent néanmoins encore peu étudiées en France alors qu'elles constituent l'un des domaines privilégiés de la sociologie américaine. Robbins B., "Othering the academy : professionnalism and multiculturalism". Social Research, $n^{\circ}$ 58, 1991, pp. 355-372.
} 
l'endroit de la jeunesse. Néanmoins, il s'adapte particulièrement ici à la thèse du «décalage», si chère à l'avant-gardisme. Selon le «dogme» romantique, l'artiste précurseur est condamné au mépris de ses contemporains. Il ne peut combler le fossé qui sépare l'innovation des perceptions coutumières. Mais, la jeunesse peut contribuer à réduire ce déficit de communication. Le jeune peut, par le style et l'énergie qu'inspirent les nouvelles générations ${ }^{23}$, incarner le mouvement et porter les changements esthétiques.

Une telle argumentation reste pour le moins sommaire, quoique efficace. Elle mésestime le poids de l'héritage culturel et la précocité d'un tel phénomène. Par ailleurs, cet argumentaire réduit la jeunesse à un ensemble homogène, partant, il aplanit les disparités sociales ct culturelles qui traversent l'ensemble du corps social, ce, quelle que soit la classe d'âge considérée. Surtout, une telle représentation ne rend pas compte de la diversification récente des modèles culturels. Le déclin du «bon goût» ou, si on préfère, la crise de la culture cultivée, fait écho à l'apparition d'une esthétique plus éclectique, parcourue d'une pluralité d'expériences radicales (punk-rock, tagg, rap...) ${ }^{24}$. A ce titre, l'exhortation à la fréquentation des musées d'art contemporain fait l'impasse sur le développement tout aussi intrigant de provocations rivales mais néanmoins absentes $\mathrm{du}$ champ légitime de la production culturelle.

Les études consacrées à l'évolution des goûts et des connaissances culturelles signalent l'apparition de nouveaux clivages. Comme hier, la multiplicité des préférences est d'autant plus grande que la connaissance des répertoires est importante. Mais, les goûts ne paraissent plus structurés seulement par l'opposition «bon goût/vulgaire», à l'origine du clivage entre culture savante et culture populaire. Deux dimensions se surajoutent aujourd'hui à ce critère: l'une renvoie aux positions adoptées face au modernisme (tradition/innovation), l'autre, à l'importance accordée au respect des conventions (conservatisme/provocation). Les échelles d'opinions, constituées à partir des jugements portés à l'égard d'un échantillon d'artistes, illustrent bien ce changement. Une enquête nationale réalisée par le Département Etude et Prospective du Ministère en offre l'exemple le plus saisissant. Selon cette étude, Nana Mouskouri, jugée trop classique, ferait l'unanimité contre elle. En revanche, Serge Gainsbourg obtiendrait, pour des raisons strictement opposées, un crédit quasi général. Bien entendu, ces opinions sont encore plus affirmées au sein des générations les plus jeunes ${ }^{25}$.

Les licux d'expression juvéniles : un territoire aux interstices

Les mécanismes décisionnels propres au secteur public suggèrent la formation d'espaces culturels abstraits, relativement sinon radicalement éloignés des territoires où s'exerce la pratique des jeunes. La culture juvénile ignore d'ailleurs la plupart du temps aussi bien les découpayes communaux que les canevas administratifs. Elle les traverse ou elle demeure, au

\footnotetext{
23 Comme le rappelle fort justement Karl Mannheim in Le problème des générations. Paris. Nathan. 1991.

24 Morin E., "Les cultures de notre culture", Sociologie, Paris, Fayard, 1984, pp. 339-365.

25 Donnat 0. Les Français face à la culture : de l'exclusion à l'eclectisme, op. cit..

${ }^{26}$ Callède J.-C.et Felonneau M., Le phénomène culturel à Bergerac : processus de differenciation des pratiques et politiques de la culture. Bordeaux, MSHA, 1981; Cavet, "Le territoire incertain de l'animation culturelle : l'exemple toulousain", Les papiers. Politique culturelle et territoire, $n^{\circ} 6$, Toulouse, Presses Universitaires du Mirail, 1989, pp. 133-143.
} 


\section{En somme, les espaces d'expression juvénile s'apparentent souvent à des territoires fixés aux interstices des lieux publics}

sociale, sinon sur le mode de la dérision. Cette révision confère sans doute à la notion de provocation tout

contraire, résolument privée, sinon intime ${ }^{26}$. En somme, les espaces d'expression juvénile s'apparentent souvent à des territoires fixés aux interstices des lieux publics.

Ce découplage s'est accentué à mesure que les organisations politiques et partisanes se sont désolidarisées des mouvements culturels. Dans les années 1970, les oppositions idéologiques coiffaient le regard porté sur les espaces urbains, les pratiques de la culture ou bien encore les conflits générationnels. La banlieue incarnait alors aussi bien l'opposition politique, le radicalisme artistique que le changement social. L'émergence de ce nouvel espace sur le devant de la scène publique a pu s'organiser sur la base d'un système d'interprétations convergentes, noué par la revendication d'une sortie de la marginalité $^{27}$.

Rarement aujourd'hui, les villes d'agglomération revendiquent réellement et structurellement leur soutien à la culture juvénile. La formation des candidats à la création rock ou rap demeure privée, c'est-à-dire assurée par les pairs. Quant à l'organisation de ce segment de la production artistique, elle continue de dépendre d'un quasimonopole marchand.

La réticence des municipalités a de multiples origines. Néanmoins, l'autonomisation progressive du phénomène culturel ajoute plus qu'elle n'enlève à la sous-représentation de l'expression des jeunes. En effet, ce processus signale une difficulté nouvelle en matière de contestation culturelle. Ainsi, l'esthétique contemporaine semble avoir définitivement renoncé à la critique son sens. Quant aux formes d'expression les plus radicales de la culture juvénile, elles empruntent des voies ou expriment des attentes souvent fort éloignées des formes convenues du discours et du débat politiques.

Ces pratiques ne peuvent donc à la fois accéder au rang des revendications et des provocations légitimes et rester associées à une classe d'âge ${ }^{28}$. Quand leur distance à l'appareil public est faible, elles intègrent le registre de l'interprétation ou du répertoire, quand elles s'en éloignent ou s'en distinguent, elles sont au mieux qualifiées d'amateurs ou abandonnées à l'exploitation - immédiatement dépréciative - du secteur marchand.

\footnotetext{
27 La chanson offre une mémoire vivante de cette période de I'histoire urbaine. Deneux J.-F., "Innovation et évocation des banlieues dans la chanson française actuelle (vers 1966-1968)" in (N.) Gérōme, (D) Tartakowski, (C) Willard, La banlieue en fête. De la marginalité urbaine à l'identité culturelle, Paris, PUF, 1988. pp. 83-95.

28 Ce dilemme parcourt l'essentiel de la musique rap. Cet univers, bien moins homogène qu'on pourrail le croire, hésite entre deux tendances fort contrastées : la composition artistique (le sample, le jeu de mots...) et la violence collective (appel à la rébellion, à la délinquance...). De ce point de vue, il rend compte d'une jeunesse fragmentée. divisée en catégories, elles-mêmes pourvues de possibilités d'action résolument inégales.
} 
Annexes

\begin{tabular}{|c|c|c|c|c|}
\hline \multicolumn{5}{|c|}{ Fréquentation des F.R.A.C. Aquitaine (1988-1989) } \\
\hline & Expositions & Dates & $\begin{array}{c}\text { Recettes } \\
\text { (vente catalogue Frs) }\end{array}$ & Visiteurs \\
\hline Bordeaux & $\begin{array}{l}\text { Robert Mapplethorpe } \\
\text { Pierre Mercier } \\
\text { Helmut Newton } \\
\text { Roman Opalka } \\
\text { Duane Michals } \\
\text { Michel Journiac } \\
\text { Pierre Molinier } \\
\text { Pierre Barès } \\
\text { Cindy Sherman }\end{array}$ & $\begin{array}{l}03 / 88-05 / 88 \\
\\
06 / 88-09 / 88 \\
10 / 88-01 / 89 \\
02 / 89-04 / 89 \\
06 / 89-09 / 89 \\
10 / 89-01 / 90\end{array}$ & $\begin{array}{l}85,00 \\
\text { pas de catalogue } \\
160,00 \\
\text { Total: } \mathbf{1 5 3 5 , 0 0}\end{array}$ & $\begin{array}{l}680 \\
\text { (dt } 85 \text { scolaires) } \\
113 \\
185 \\
306 \\
256 \\
276 \\
\text { Total : } 1816\end{array}$ \\
\hline Dax & $\begin{array}{l}\text { «Dax : collections } \\
\text { pour une région» } \\
\text { Jean-Michel Albérola } \\
\text { Autoportraits } \\
\text { Gestes de peintures } \\
\text { Patrick Tosani } \\
\text { Clegg et Guttmann }\end{array}$ & $\begin{array}{l}03 / 88-05 / 88 \\
06 / 88-09 / 88 \\
10 / 88-01 / 89 \\
02 / 89-04 / 89 \\
06 / 89-09 / 89 \\
10 / 89-01 / 90\end{array}$ & $\begin{array}{l}30,00 \\
\text { pas de catalogue } \\
\text { Total : } 322,00\end{array}$ & $\begin{array}{l}135 \\
243 \\
\text { (dt } 36 \text { scolaires) } \\
150 \\
549 \\
\text { (dt } 449 \text { scolaires) } \\
300 \\
505 \\
\text { (dt } 325 \text { scolaires) } \\
\text { Total : } \mathbf{1 8 8 2}\end{array}$ \\
\hline Agen & $\begin{array}{l}\text { «Agen : collections } \\
\text { pour une région» } \\
\text { Luc Lauras }\end{array}$ & $\begin{array}{l}03 / 88-05 / 88 \\
06 / 88-09 / 88\end{array}$ & 20,00 & $\begin{array}{l}331 \\
\text { (dt } 202 \text { scolaires) } \\
2085 \text { (fréquent. } \\
\text { totale du musée) } \\
\text { Total : } \mathbf{2 4 1 6}\end{array}$ \\
\hline Bayonne & $\begin{array}{l}\text { Richard Baquié } \\
\text { Pascal Convert } \\
\text { Juan Munoz } \\
\text { Susana Solano }\end{array}$ & $06 / 88-09 / 88$ & Total : $\mathbf{1 6 4 , 5 0}$ & $\begin{array}{l}7751 \\
\text { (fréquent. } \\
\text { totale du musée) } \\
\text { Total : } 7751\end{array}$ \\
\hline Périgueux & $\begin{array}{l}\text { «Périgueux : collections } \\
\text { pour une région» } \\
\text { Maya Andersson } \\
\text { Sculptures } \\
\text { La légende de l'alphabet } \\
\text { Georges Rousse } \\
\text { Jean-Paul Thibeau }\end{array}$ & $\begin{array}{l}03 / 88-05 / 88 \\
06 / 88-09 / 88 \\
10 / 88-01 / 89 \\
02 / 89-04 / 89 \\
06 / 89-09 / 89 \\
10 / 89-01 / 90\end{array}$ & $\begin{array}{l}140,00 \\
454,50 \\
180,00 \\
589,50 \\
750,00 \\
315,00 \\
\text { Total : } \mathbf{2 4 2 9 , 0 0}\end{array}$ & $\begin{array}{l}707 \\
\text { (dt } 113 \text { scolaires) } \\
859 \\
367 \\
332 \\
1187 \\
\text { (dt } 175 \text { enfants) } \\
681 \\
\text { (dt } 254 \text { scolaires) } \\
\text { Total : } 4133\end{array}$ \\
\hline
\end{tabular}

Source: (P.) Le Moigne, L'émergence d'une scène publique de la culture. Analyse sociologique de l'action culturelle de six villes du Sud-Ouest (1977-1990), Thèse pour l'obtention du Doctorat de Sociologie, sous la direction de F. Chazel, Bordeaux, Université de Bordeaux II, 1995, pp. 313-314. 


\section{$\ll A$ hearing for legitimate provocation »}

Public action, contemporary aesthetics and youth culture

This article looks at the diverse logistics which provide a back-up, both from the state and local authorities to the public plebiscite of contemporary art. These aesthetic, radical and iconoclastic canons have a great deal in common with both the past and present forms of youth culture. However, the territories of these two cultures only very rarely overlap. Young people's creative achievements, when simply labelled as udangerous self-expression" nevertheless continue to be associated with private, commercial and "intimist" business. On the other hand, public promotion of the visual arts relates rather more to a "fashionable radicalism"; it contributes to a hearing for legitimate provocation, leading to tensions but also to a reappraisal of cultural qualifications and skills.

\section{El espacio de provocaciones legitimas}

Accion publica estetica contemporanea y cultura juvenil Este articulo presenta las diferentes lógicas de acción que sostienen, tanto de parte del Estado como de las municipalidades, el plebiscito público del arte contemporáneo. Esos cánones estéticos, radicales e iconoclastas, mantienen numerosas afinidades con las formas antiguas y modernas de la cultura juvenil. Sin embargo, los territorios de esas dos culturas no se imbrican nunca realmente. La creación de los jóvenes, cuando no es reducida al estatuto de "expresión peligrosa", queda asociada a una explotación privada, comercial o "intimista". Por el contrario, la promoción pública de la artes plásticas se asemeja, más bien, a "un radicalismo mundano "; contribuye a la formación de un espacio de provocaciones legítimas, portador de tensiones, pero también de una recomposición de las calificaciones y de las competencias culturales.

\section{Der Raum der legitimen Provokationen}

Offentliche Aktion, zeigenössische Ästhetik und jugendliche Kultur

Dieser Artikel legt die verschiedenen Handlungslogiken dar, die, sowohl von Seiten des Staates als auch der Stadtverwaltungen, das öffentliche Plebiszit für zeitgenössische Kunst stützen. Diese ästhetischen Kanons, radikal und bilderstürmerisch, unterhalten zahlreiche affinitäten zu den alten und modernen Formen der jugendlichen Kultur. Trotzdem kommen die gebiete dieser beiden Kulturen nie wirklich zu einer Deckung. Wenn die Schöpfung der jungen Leute nicht auf den Stand des "gefährlichen Ausórucks" reduziert ist, bleibt sie dennoch einer privaten, kommerziellen oder «intimistischen» Nutzung verbunden. Im Gegensatz dazu ist die öffentliche Förderung der plastischen Künste eher dem «mondänen Radikalismus» verwandt. Sie trägt zur Schaffung eines Raumes der legitimen Provokationen bei, der zwar Träger von Spannungen ist, aber auch die Qualifikationen und kulturellen Kompetenzen wiedererstehen lässt. 